\title{
ONLINE LEARNING IN PANDEMIC - AN ANALYSIS OF PARENTAL PERSPECTIVE
}

\author{
1 Haritha B, 2 Challapalli Praseeda, \\ 1 Research Scholar, 2 Professor, \\ 1Department of Management Studies, SRMIST-Vadapalani campus, Chennai \\ 2 Department of Management Studies, SRMIST-Vadapalani campus, Chennai \\ 1hb5184@srmist.edu.in,2praseedc@srmist.edu.in,
}

\begin{abstract}
The COVID-19 pandemic has caused more than 1.6 billion children and youth to be out of school in 161 countries. The crisis has highlighted flaws in educational programs while also providing opportunities to reshape schooling. Climate change, technological disruptions, and globalized communication are all increasing the likelihood of such crises. These issues have given rise to doubts and debates regarding the dilution of the educational systems and dubiousness being felt by the parents regarding the same. As a result of the transition of homes into classrooms, parental engagement and parental involvement have emerged as major influencing factors of online education. As parents are the major stakeholders in the online educational format. They have always played an important role in their children's education. However, in the aftermath of the pandemic, the parent's position has shifted dramatically. Parents now bear a significant amount of responsibility for their children's education. This has given rise to conflicting emotions in the parents regarding the dilution of the education system and more importantly the onus of child's education shifting to the parents thereby reducing the responsibility of the schools and teachers. Often parents have been heard expressing their resentment at the reconfigured roles and responsibilities caused by the shift. The present study intends to focus in their perspectives on online education. The present study attempts to understand the dilemma being faced by the parents.
\end{abstract}

Keywords: Parents Perception, covid-19, pandemic online classes, online teaching Effectiveness, Online Education, Technological facility, Online class time, Parents satisfaction, Parents involvement and Parents role change.

\section{Introduction}

The entire global education system was caught unprepared by the demand to shift to online mode made by the surging pandemic which started its significant impact from December 2019. The educational institutions around the world had to adopt relevant technological support systems, the governing bodies had to create appropriate guidelines and finally the students and their families had to adjust to the demands of this new normal. The resultant environment may be referred to as equivalent to the flipped classroom mode which propagates collaborative learning. 
Parents have always played an important role in their children's education. However, in the aftermath of the pandemic, the parent's position has shifted dramatically. Parents now bear a significant amount of responsibility for their children's education. In the 'new normal,' parents and other caregivers are expected to play a larger role in their child's learning and growth than they have in the past. So, since the majority of schooling now takes place at home rather than on a school campus, even without the physical presence of teachers.

The COVID-19 pandemic has caused more than 1.6 billion children and youth to be out of school in 161 countries. This is close to $80 \%$ of the world's enrolled students. (Jaime Saavedra, March 30, 2020) According to experts, the global COVID-19 pandemic might result in the loss of an entire year of education. (Premium Times, June 25, 2020) The crisis has highlighted flaws in educational programs while also providing opportunities to reshape schooling. Climate change, technological disruptions, and globalized communication are all increasing the likelihood of such crises. These issues have given rise to doubts and debates regarding the dilution of the educational systems and dubiousness being felt by the parents regarding the same. The present study attempts to understand the dilemma being faced by the parents.

The Makinsy study (2012), identifies India has 120 million internet users and has the potential to contribute 3.3 percent of the country's GDP by 2015. According to Datareportal.com, India will have 624 million internet users by January 2021, implying an obvious and broad online presence in the country. The Covid 19 epidemic, which compelled the use of the internet at all levels of society, from home necessities to educational obligations to employment reporting, may be the reason for this astonishing 47 percent increase in internet usage from 2020 to 2021. As a result of the transition of homes into classrooms, parental engagement and parental involvement have emerged as major influencing factors of online education. As parents are the major stakeholders in the online educational format, the current study intends to focus in their perspectives on online education.

\section{Impact of Covid 19 on Students}

The influence of the COVID-19 pandemic on children's psychological well-being, prior research has raised serious concerns about children's physical and mental health during healthrelated calamities (Danny Horesh 2020, Jörg M. Fegert, 2020 Cross ref Winnie W. Y. Tso 2021). During a disease pandemic with protracted periods of school closure, even healthy children may be at danger of psychological difficulties such as diminished emotional, social functioning, and physical activity. (Winnie W. Y. Tso, 2021). The influence of the COVID-19 pandemic on children's psychological well-being, prior research has raised serious concerns about children's physical and mental health during health-related calamities (Danny Horesh 2020, Jörg M. Fegert, 2020 Cross ref Winnie W. Y. Tso 2021). COVID-19 epidemic, and the consequent related disease control measures such as school closures and isolation, will have a negative impact on children's and parents' emotional well-being. During a pandemic with protracted periods of school closure, even healthy children may be at danger of psychological difficulties such as diminished emotional, social functioning, and physical activity. (Winnie W. Y. Tso, 2021). Therefore there is a need to ascertain factors that can promote 
psychosocial wellbeing within families during the COVID-19 pandemic. This will help in building a knowledge base to inform the development of effective strategies to mitigate adverse outcomes due to COVID-19. Furthermore, due to a lack of resources in certain income levels, home educating might be challenging for children from low-income households is the other area of concern. Children are more susceptible to their surroundings, which can have a longterm impact on their health and productivity as adults (Wang G, 2020 Cross ref Winnie W. Y. Tso 2021). Although the impact of parental anxiety on children's PA during pandemics has yet to be directly investigated, there is evidence that parental anxieties about social and environmental factors (e.g., fear, safety, and risk) can have an impact on their child's PA (O'Connor and Brown, 2013; Weir et al., 2006 cross ref Gavin R. McCormack, 2020). As a result, parent concern over the COVID-19 pandemic may have an impact on their children's PA and SBs (Gavin R. McCormack, 2020).

In the early months of the COVID-19 pandemic, preliminary research found that children's mental well-being (MWB) was particularly sensitive to the pandemic and accompanying public health limitations (Prime H, 2020 and Commisioner C, 2020 cross ref Amanda S. Gilbert, 2021). Children risk social isolation, scholastic delays as a result of in-person school closures, and stress as a result of financial constraints many families encounter as a result of COVID-19 limitations causing parents and caregivers to lose their jobs (Lee J, 2020, Gupta S,2020, Golberstein E, 2020 and Golberstein E, 2019 cross ref Amanda S. Gilbert, 2021). Furthermore, children in elementary school may struggle to comprehend the health dangers of COVID-19 and the disruptions to everyday life brought on by lockdown measures, creating fear and anxiety (Prime H, 2020 cross ref Amanda S. Gilbert, 2021). COVID-19 limitations are also linked to increased sedentary behavior (SB) and decreased physical activity (PA), all of which contribute to children's poor mental health and well-being (Qin F, 2020 and Rodriguez-Ayllon M, 2019 cross ref Amanda S. Gilbert, 2021). Poor MWB, inadequate PA, and elevated SB in infancy may have long-term and substantial health implications, according to studies (Wade M, 2020 and Van Ekris E, 2016 cross ref Amanda S. Gilbert, 2021).

It is common knowledge that, transmission is higher in densely-packed, indoor spaces, and although the danger to children may not be as high as the risk to the adults teaching them, the virus does seem to evoke an extreme reaction in a very small number of pediatric cases. After all, they're not exactly known for their fastidious hygiene. And when that is combined with the other stresses of living in isolation under quarantine, it may have some serious consequences delaying their cognitive, emotional and social development. Its disadvantaged children who pay the greatest price here, as they will fall the furthest behind, and have the fewest resources available to 'catch up' once the pandemic threat has passed," says Armitage (David Robson, 2020 BBC). The present study makes an attempt to understand these dimensions from a parent point of view. The study is initiated with a description of the historical development of online education, followed by the emerging landscape of the online education perpetuated by the pandemic and the consequent emergence of blended learning. A review of relevant literature is made and relevant research questions are raised, hypnotized and analyzed to culminate in meaningful insights. 


\section{The History of Online Education}

Online education has evolved over a period of time. The 1950s, witnessed slide projectors and television-based classrooms used for educating but only in a one way mode. One of the world's first examples of online learning dates from 1960 at the University of Illinois in the United States. Students began studying via computer terminals that were interconnected to establish a network, despite the fact that the internet had not yet been invented. The University of Toronto delivered the first entirely online course in 1984. In India, understanding the potential of electronic media the UGC started "countrywide classrooms" way back in 1984. In the early 1990s, the Open University in the United Kingdom was one of the first universities in the world to provide online distance learning.

In today's world, online learning is transforming the way we learn beyond recognition. Online learning is anticipated to increase by leaps and bounds in the near future, due to the widespread availability of high-speed internet and the usage of new technologies such as 4G and the soonto-be-released 5G. In 2019, the global market for online learning is estimated to be worth $\$ 187.87$ billion, up 400 percent from just six years ago. This extraordinary expansion has been enabled not just by the constantly changing technological landscape, but also by the spread of education throughout the emerging global demand Colleges and institutions are no longer the only places where one may learn online. Online learning has permeated into the pedagogy from primary school. The current COVID-19 epidemic emphasizes the significance of online learning in today's educational system, as it has shown to be a boon to both students and instructors who are unable to attend school owing to the danger of illness transmission. Beyond high school, online learning is rapidly growing in popularity among pre-university students. (Soumik Sarkar 2020, Adamas University).

\section{Timeline of Early Online Education Pioneers}

\begin{tabular}{cccccccc}
1950 & & 1960 & & 1970 & & 1980 \\
\hline & 0 & 0 & $\bullet$ & 0 & 0 & 0 & 0 \\
1955 & & 1965 & & 1975 & 1985
\end{tabular}

Sources: physics Illinois.edu/ ourroots.ca/ web.njit.edu/ eric.ed.gov/ coastline.edu/ Adamas University.

\section{The Emerging Learning Landscape}

Blending learning is primarily understood as an approach or a model that includes online education using a structured combination of educational media, teacher-led support/guidance, various sources of information, text-based and electronic media practices for the purpose of submitting, implementing, and evaluating the instruction. Thomson (2002), M. Kemal Karaman (2011). Blended learning is the current trend of supplementing face-to-face (FTF) classes with web-based resources.(Garrison \& Kanuka, 2004 cross ref M. Victoria López-Pérez 2011). The word blended indicates a new trend in higher education of combining text-based asynchronous Internet technologies with face-to-face learning, which is commonly referred to 
as blended learning. 2004 (Garrison). It's critical to separate blended learning from other types of education that include online components. First and foremost, blended learning differs from improved classroom or entirely online learning. However, it is unclear how much, if any, online learning is included into blended learning. 2004 (Garrison).

Focusing on the characteristics of the Internet highlight the fact that the interactive capabilities of Internet communication technologies are responsible for much of the happiness and success of blended learning experiences (Garrison \& Cleveland- Innes, 2003; Swan, 2001 cross ref Garrison 2004 ). It's Critical to understand "Blended Learning" as a combination of the use of online learning in conjunction with traditional face-to-face education in a variety of learning settings to assist teaching and learning (Duhaney, 2004; Klein 2006 Cross ref Renee 2011). Blended learning courses are becoming increasingly important, according to the Centre for Educational Research and Innovation (CERI, 2005) yet it is stressed that ICTs is being created to complement, not replace, conventional modes of learning (Mitchell \& Forer, 2010: 78 cross ref M. Victoria López-Pérez 2011). There is also an arguemnt that sugegsts athat learning patterns and behaviours may alter as a result of using mixed learning materials. (Huon, Spehar, Adam, \& Rifkin, 2007; M. Victoria López-Pérez, 2011; Huon, Spehar, Adam, \& Rifkin, 2007). With the rise of online technology and the increased use of the internet and social media for education in the twenty-first century, a new social constructivism has emerged, allowing teachers to reach out to each student and learners to share their ideas and views with their peers. Mckay et al. (2018) cross ref Ritimoni Bordoloi 2021). Several research have been performed on how online learning has revolutionised the area of education in the twenty-first century and in what ways they are such gratifying experiences. Sir (Daniel (2020) cross ref Ritimoni Bordoloi 2021) mentioned how several governments have ordered institutions to switch from face-to-face to online teaching and virtual education for the learners, citing the Covid-19 pandemic as the greatest challenge the world's education systems have currently faced. The Covid -19 has made virtual learning a vital tool to impart education due to the lack of possibility of imparting education in the traditional classrooms with physical interaction in the ealry stages of covid. After the second wave of the pademic blended learning has emerged as regular household phenomena. Given below is the graph displaying the impact of covid on both online and blended learning.

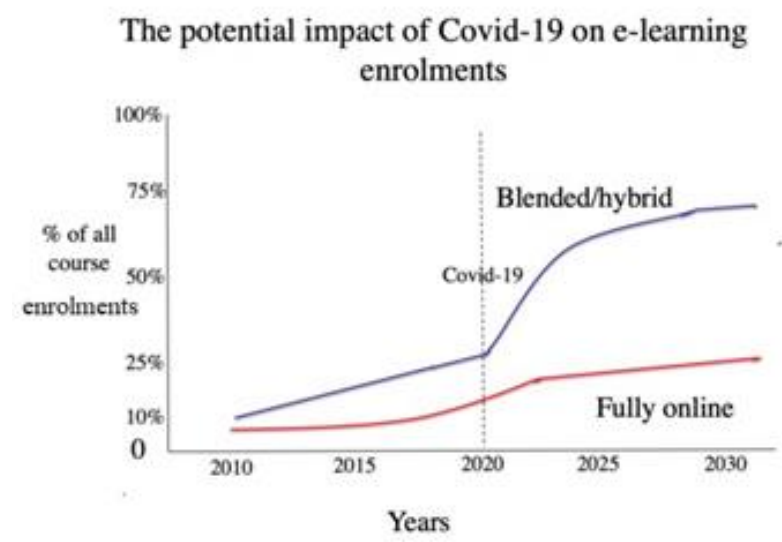

Source: University Affairs Magazine/ Adamas University. 
Despite the widespread use of blended learning tools across the globe through the use of technological interventions which have eased the implemenmtation of online education, still they have not been able to mimic the physical classroom environment and the riogours associated with it. Even with advanced AI technology there has been no way found to asses if the students are paying attention in reality or if they are just shwoing their online presence. This gives rise to a research question of "whether online education has reduced student participation to mere online presence"? whether the existing school related factors are sufficient for sucessful educational expreince for the student?

H1 There is a definite impact of online education and pedagogy on the learning levels of students.

\section{Parental Role in Blnded Learnig}

The shift to distance/online learning has a significant influence on all stakeholders in the educational process (Bokayev et al 2020). Students may have had significant problems in sustaining their academic motivation due to a rapid transition in the delivery style of instruction and an unclear future (Zaccoletti, 2020). To minimise disturbance and ensure that students could get instruction remotely during school closures, teachers implemented novel techniques such as distant learning programmes and open educational tools and platforms. (2020, Zaccoletti) Because online learning via digital technology is a component of a young child's "multimodal living world," it should be contextualised and capitalised to assist teachers, parents, and children in developing agentic multimodal behaviours. (2020 Chuanmei Dong) Chuanmei Dong cross-ref (2020). This abrupt transition to remote learning, as well as the problems it poses, are cause for worry since, without adequate parental support, these changes may increase the risk of parents suffering parenting stress and burnout, which might negatively influence children. Griffith (Griffith, 2020) Eva Yi Hung Lau cross-ref (2020). The government and schools expected parents to assist establish positive learning environments at home and monitor their children's challenges and Miao Liments with staying on track with their work (Baza Yurist (Lawyer database), 2020 cross ref Baurzhan Bokayev 2020).This implies that parents are willing and able to support their children's education at home. A study undertaken by Mirza \& Al-Abdulkareem (2011) conducted in Zayed University showed thar parents of female students were appreciative of the fact that the online mode of education has opened up newer vistas of learning especially for the girl students. This suggests that the online mode of education is providing higher opportunities to girl's students of certain regions who were inhibited by the sociocultural customs and traditions from pursuing education in the offline mode.

Unfortunately, many children's homes do not provide a caring or safe atmosphere for them. The imposition of social isolation has resulted in an increase in domestic abuse and family violence all across the world (Usher et al., 2020 cross ref Baurzhan Bokayev 2020). An exploratory research on the views of Chinese parents' about kindergarten kids' online learning during the COVID-19 epidemic, and found that most parents had unfavourable opinions regarding online learning (Dong et al., 2020) Eva Yi Hung Lau cross-ref (2020). 
In the new normal of education, the role of parents as study buddies is becoming increasingly important. The parents' experiences utilizing self-learning modules to provide instruction to their children. This clarifies the topics and core category of parents' or guardians' experiences as study partners in the new normal of education. L 2020 (Daryl Benedict). The present study therefore aims to examine the parental expectation and involvement in the context of the demands of blended learning.

H2: There is an impact of parental involvement on institutional factors.

\section{Parental expectation}

Rising parental expectations about the role of ICTs in their children's futures, as well as their discourses about the internet's opportunities and risks, and the practices through which they mediate their children's engagement with technology, all contribute to the formation of distinct social contexts in which children are socialized to online practices. Parents' expectations, anxieties, and behaviors differ depending on their education, socioeconomic background, and parenting culture (Livingstone et al., 2015). Despite the fact that the term "parental expectations" has been defined in a variety of ways in the literature, most researchers define it as realistic beliefs or judgments that parents have about their children's future achievement as evidenced by course grades, highest level of schooling attained, or college attendance (e.g., Alexander et al. 1994; Glick and White 2004; Goldenberg et al. 2001 cross ref Yoko Yamamoto 2010). Parental expectations are based on an evaluation of the child's academic skills as well as the resources available to support a specific degree of performance. (Gill and Reynolds 1999, cross-ref Yoko Yamamoto in 2010). The significance of parental expectation is stressed based the premise that kids whose parents have high expectations earn better grades, score higher on standardized exams, and stay in school longer than students whose parents have low expectations (Davis-Kean 2005; Pearce 2006; Vartanian et al. 2007 cross ref Yoko Yamamoto 2010). Student ambition to succeed in school, scholastic and social resiliency, and college aspirations are all connected to high parental expectations (Hossler and Stage 1992; Peng and Wright 1994; Reynolds 1998 cross ref Yoko Yamamoto 2010).

\section{Review of Literature}

The emergence of the corona pandemic has had a significant impact on education, with a huge number of pupils stranded at home, staring at a laptop/computer/tablet/mobile screen and passively absorbing advice (Dai and Lin, 2020 quoted in Khan 2021). Zaccoletti, (2020) opines that parental help has become critical, particularly for younger children who are unable to manage their allocated learning tasks alone requiring parental guidance at home which in turn had its own drawbacks as these techniques created problems since not all parents could work alongside their children, and not every family had the necessary technological gear, such as laptops with internet access. Often parental concerns are also found to be expressed regarding the extensive and sometimes uncontrolled use of internet and electronic gadgets by the students. Yet Hatzigianni \& Margetts, (2014) in their study identify that parents, in particular, had positive attitudes regarding young children's computer use, believing that children should learn useful technical skills and be trained on how to use computers to improve their academic development and future career possibilities (Perradvoci et al., 2016 cross-ref Chuanmei 
Dong 2020). Parenting styles, imaginaries, and discourses, according to studies on early childhood education, shape the ways by which parents direct their children's interaction with tablets, smartphones, and applications, and therefore promote or impede their learning (Marsh et al., 2015; Plowman et al., 2008, 2010). Giovanna Mascheroni, (2016) in their study which is mostly exploratory in nature, reveal that electronic enablers of learning like the tablets have swiftly gained popularity among both young children and their parents, with the touchscreen interface being considerably easier for youngsters to operate than the keyboard or mouse required for a laptop or desktop computer.

On the positive side the students get accustomed to the self-disciple and self-control and focused learning demanded by the online mode of education. The educational institutions on the other hand had to develop systems, faculty and procedure to facilitate online teaching, the parents were also impacted both from economic and non-economic dimensions. Economically many parents had to face challenges of livelihood created by the economic recession caused by the Covid on one hand and the need to provide for the technological support to their children to continue with their education on the other hand. These aspects suggest high expectations of the parents in relation to the institutional support systems to be arranged for effective online learning. The hypothesis adopted therefore is

H3: There is an impact of institutional factors on parental satisfaction

Parents have had to assume the pivotal role in ensuring the learning of their wards at home in the absence of the controlling presence of the teacher. When schools are closed, there is an increase in communication between kids and their parents and other adults (Eames et al., 2010 cross ref Abuhammad 2020). School closures can reduce mortality by lowering illness transmission and incidence (Abuhammad, 2020a; Anderson et al., 2020; Wenham et al., 2020) cross ref Sawsan Abuhammad 2020). Examining the degree of education of parents is one approach to evaluate the likelihood of favorable outcomes, since research has shown that this element has a substantial influence on children's academic performance (UNESCO, 2000 cross ref Baurzhan Bokayev 2020). Even with the best intentions, parents with lower levels of education face additional challenges in promoting their children's learning, and an online learning environment that asks parents to be more active could intensify this disparity. Another concern is whether the economic and social impact of the Covid-19 pandemic would impair parents' capacity to change their level of involvement sufficiently in order to have positive results, and whether this ability would differ depending on the parents' educational level.

The arguments given above demand a definite role from the parents in terms of their expectations and involvement. These dimensions are therefore adopted as moderators, while examining the role of institutional factors on parental satisfaction with online learning. 


\section{Conceptual Framework}

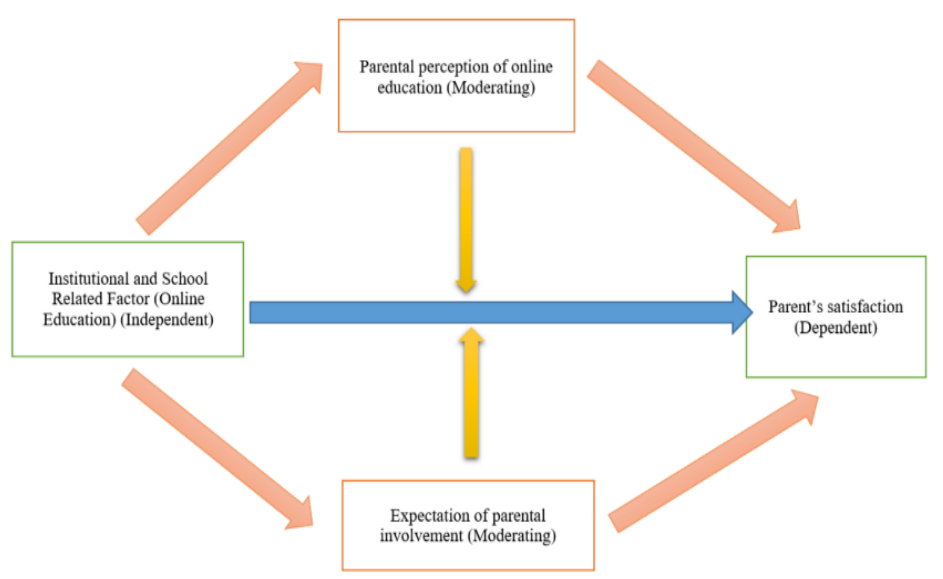

\section{Objectives of the Study}

- To understand the impact of Institutional and School Related Factor (Online Education) and Parent's satisfaction.

- To examine the role of Parental perception of online education and Parent's satisfaction.

- To study the impact of Expectation of parental involvement and Parent's satisfaction.

- To understand the role of school related factors on parental perception and involvement with their child's online education.

The study uses Descriptive research design because an attempt is made to describe the role of Institutional and School Related Factor (Online Education) and its impact on Parent's satisfaction with the moderating role of Expectation of parental involvement and Parental perception of online education. The Sample of the study is 102 Parents of school children. The sample has been selected through Non probability convenience sampling.

\section{Analysis and Discussion}

The data collected though the online mode form the parent of school children across the city of Chennai, Tamil Nadu, India using the google forms was analyzed using the SPSS, The Cronbach Alpha of the sample is .779 suggesting good reliability of the dataset. Further an effort was made to analyses the various hypotheses adopted using anova and Regression. Finally the test of moderation was made using process macro.

H1: School Related Factor (Online Education) and Parent's satisfaction) ANOVA ${ }^{a}$

\begin{tabular}{|cc|c|c|c|c|c|}
\hline \multicolumn{2}{|c|}{ Model } & Sum of Squares & Df & Mean Square & F & Sig. \\
\hline \multirow{4}{*}{1} & Regression & 2.354 & 1 & 2.354 & .959 & $.330^{\mathrm{b}}$ \\
& Residual & 245.489 & 100 & 2.455 & & \\
& Total & 247.843 & 101 & & & \\
\hline
\end{tabular}

As the significant value is greater than 0.05 , so the $\mathrm{H} 1$ is accepted. 
Hence there is significant relationship between Institutional and School Related Factor (Online Education) and Parent's satisfaction. The results are reflective of the ecological systems theory of Urie Bronfenbrenner (1979 cross ref; Bronfenbrenner \& Morris, 2006) which says that there is a relationship between the "series of environmental systems or contexts" that interact between the child and parent relationship and school and the child's performance in school is one of them. The parental satisfaction with school related contextual factors is one of the major factors that needs to be considered especially in the online school environment.

\section{H2: Parental perception of online education and Parent's satisfaction}

ANOVA $^{\mathrm{a}}$

\begin{tabular}{|cc|c|c|c|c|c|}
\hline \multicolumn{1}{|c|}{ Model } & Sum of Squares & Df & Mean Square & F & Sig. \\
\hline \multirow{4}{*}{1} & Regression & 22.271 & 1 & 22.271 & 9.873 & $.002^{\mathrm{b}}$ \\
& Residual & 225.572 & 100 & 2.256 & & \\
& Total & 247.843 & 101 & & & \\
\hline
\end{tabular}

As the significant value is lesser than 0.05 , so the $\mathrm{H} 2$ is Rejected.

The significance value of .002 suggests that there is no significant impact of Parental perception on online education and Parent's satisfaction. Though the impact of school related factors on parental perception was found insignificant as the alternate hypothesis was rejected and null was accepted.

Hence there is significant relationship between Parental perception of online education and Institutional and School Related Factor (Online Education). The Parental perception of online education and Institutional has an impact on School Related Factor (Online Education). The Technology Acceptance Model (TAM) (Davis et al., 1989), underlines the importance of the parental perception and their beliefs of the usefulness of technology in enhancing the academic performance of their ward is defining factor OD parental satisfaction with the use of technology by the institution. The perceived usefulness of online education therefore justifies its usage and thereby created parental satisfaction. Despite the dictates of the model, the present pandemic scenario makes this relationship between parental perception and satisfaction questionable given the undeniable need for online education to continue schooling within the given limitations of movements and need for social distancing.

\section{H3: Expectation of parental involvement and Parent's satisfaction}

ANOVAa

\begin{tabular}{|cc|c|c|c|c|c|}
\hline \multicolumn{1}{|c|}{ Model } & Sum of Squares & Df & Mean Square & F & Sig. \\
\hline \multirow{4}{*}{1} & Regression & 12.087 & 1 & 12.087 & 5.127 & $.026^{\mathrm{b}}$ \\
& Residual & 235.756 & 100 & 2.358 & & \\
& Total & 247.843 & 101 & & & \\
\hline
\end{tabular}

As the significant value is greater than 0.05 , so the $\mathrm{H} 4$ is accepted. 
Hence there is significant relationship between Expectation of parental involvement and Parent's satisfaction, suggesting the existence of impact of influence of parental involvement on Parent's satisfaction. Parental involvement is often discussed by the attachment theory which highlights the role of parents in "establishment, maintenance, and consequences of affectionate bonds between parents and children" which further lead to parental involvement.

\section{H4: Impact of School Related Factor on Parental Involvement}

ANOVA ${ }^{\mathrm{a}}$

\begin{tabular}{|cc|c|c|c|c|c|}
\hline \multicolumn{1}{|c|}{ Model } & Sum of Squares & Df & Mean Square & F & Sig. \\
\hline \multirow{4}{*}{1} & Regression & .020 & 1 & .020 & .002 & $.966^{\mathrm{b}}$ \\
& Residual & 1076.147 & 100 & 10.761 & & \\
& Total & 1076.167 & 101 & & & \\
\hline
\end{tabular}

As the significant value is greater than 0.05 , so the $\mathrm{H} 5$ is accepted.

Hence there is significant relationship between Expectation of parental involvement and Institutional and School Related Factor (Online Education). Hoover Dempsey and Sandler (1995) have made and extensive study of the parental involvement in the education of a child and have developed a model of 6 levels of parental involvement. The role of parents is considered crucial to help the students face school related issues. The conclusion finds more meaning in the present-day context of online education where the child faces school and teachers only viva the online mode and has no specific controlling factor.

\section{The moderation analysis}

The role of parental expectation and parental perception have been taken as the moderators for this study. The model one tests the moderation impact of parental involvement on the relationship between institutional or school related factors and parental satisfaction.

Model 1 - Parental Perception as a Moderator

Model Summary

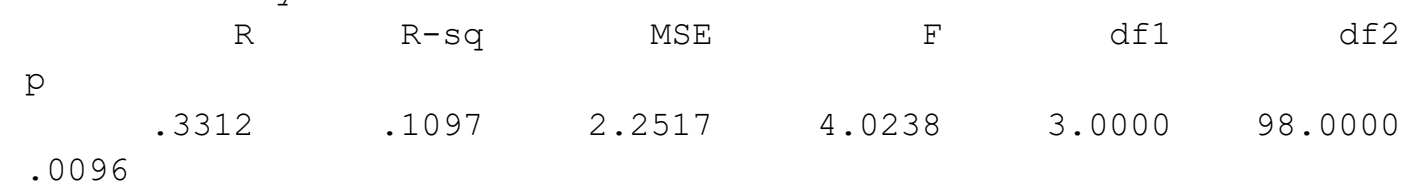

\begin{tabular}{|c|c|c|c|c|c|c|}
\hline & coeff & se & t & $\mathrm{p}$ & LLCI & ULCI \\
\hline Constant & 4.9953 & 1.6773 & 2.9782 & .0037 & 1.6668 & 8.3237 \\
\hline School_I & -.1147 & .1628 & -.7045 & .4828 & -.4377 & .2084 \\
\hline percepti & .1769 & .2108 & .8390 & .4035 & -.2415 & .5952 \\
\hline Int_1 & .0061 & .0199 & .3078 & .7589 & -.0333 & .0456 \\
\hline
\end{tabular}




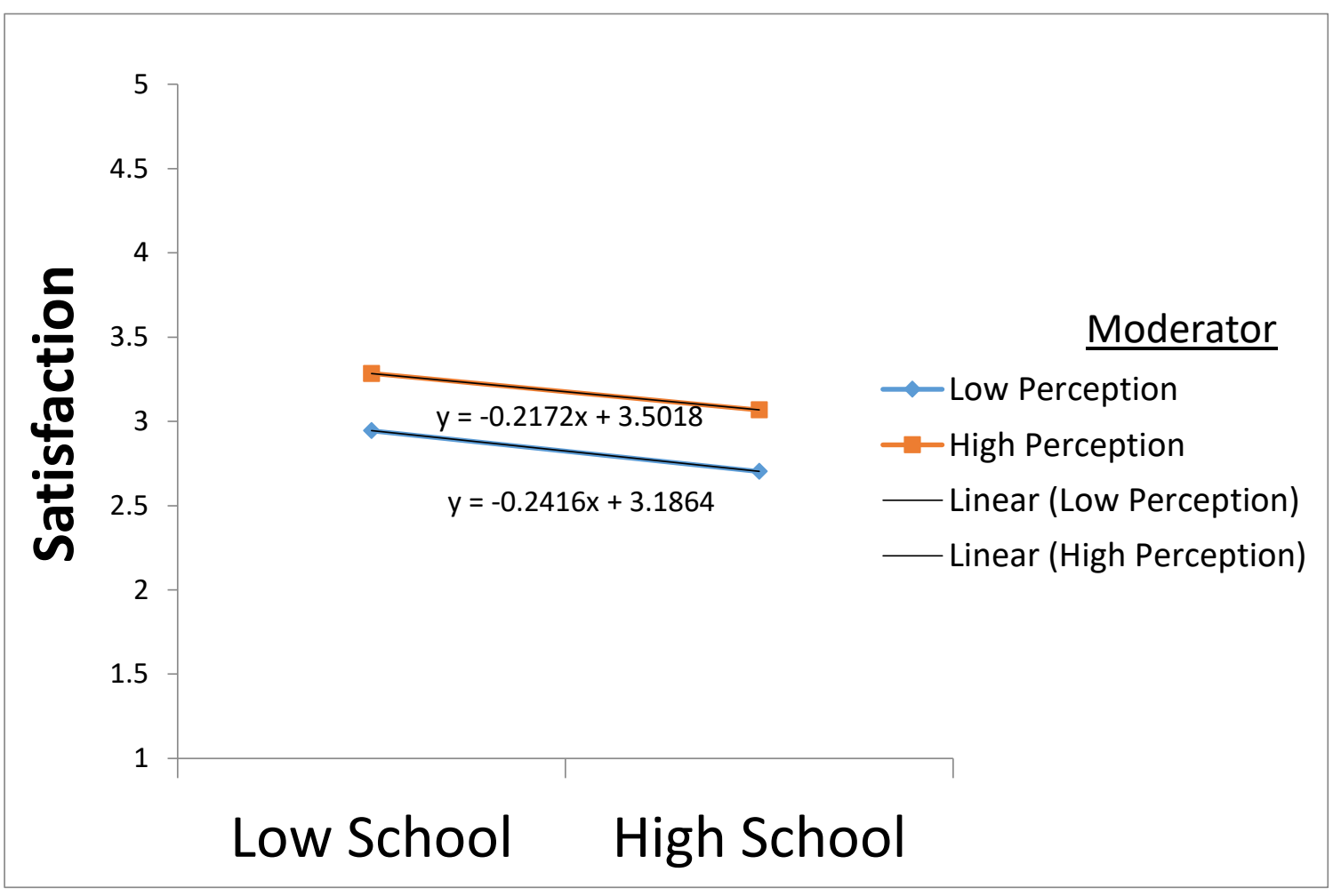

It is clearly seen that the parental perception is showing slightly negative impact on the outcome variable which is parental satisfaction while interacting with the institutional or school related factors.

Model 2 Parental expectation as a Moderator

Model Summary
$\mathrm{R}$
$\mathrm{R}-\mathrm{sq}$
MSE
F
$\operatorname{df} 1$
df2

$\mathrm{p}$
.2427
.0589
2.3800
2.0451
3.0000
98.0000

.1125

\begin{tabular}{|lrrrrrr|}
\hline Model -2 & \multicolumn{7}{c}{} \\
\hline & coeff & se & t & p & LLCI & ULCI \\
\hline constant & 4.5257 & 1.7957 & 2.5202 & .0133 & .9621 & 8.0893 \\
\hline School_I & -.0152 & .1530 & -.0997 & .9208 & -.3189 & .2884 \\
\hline involvem & .1752 & .1959 & .8942 & .3734 & -.2136 & .5639 \\
\hline Int_1 & -.0036 & .0166 & -.2196 & .8266 & -.0365 & .0292 \\
\hline
\end{tabular}




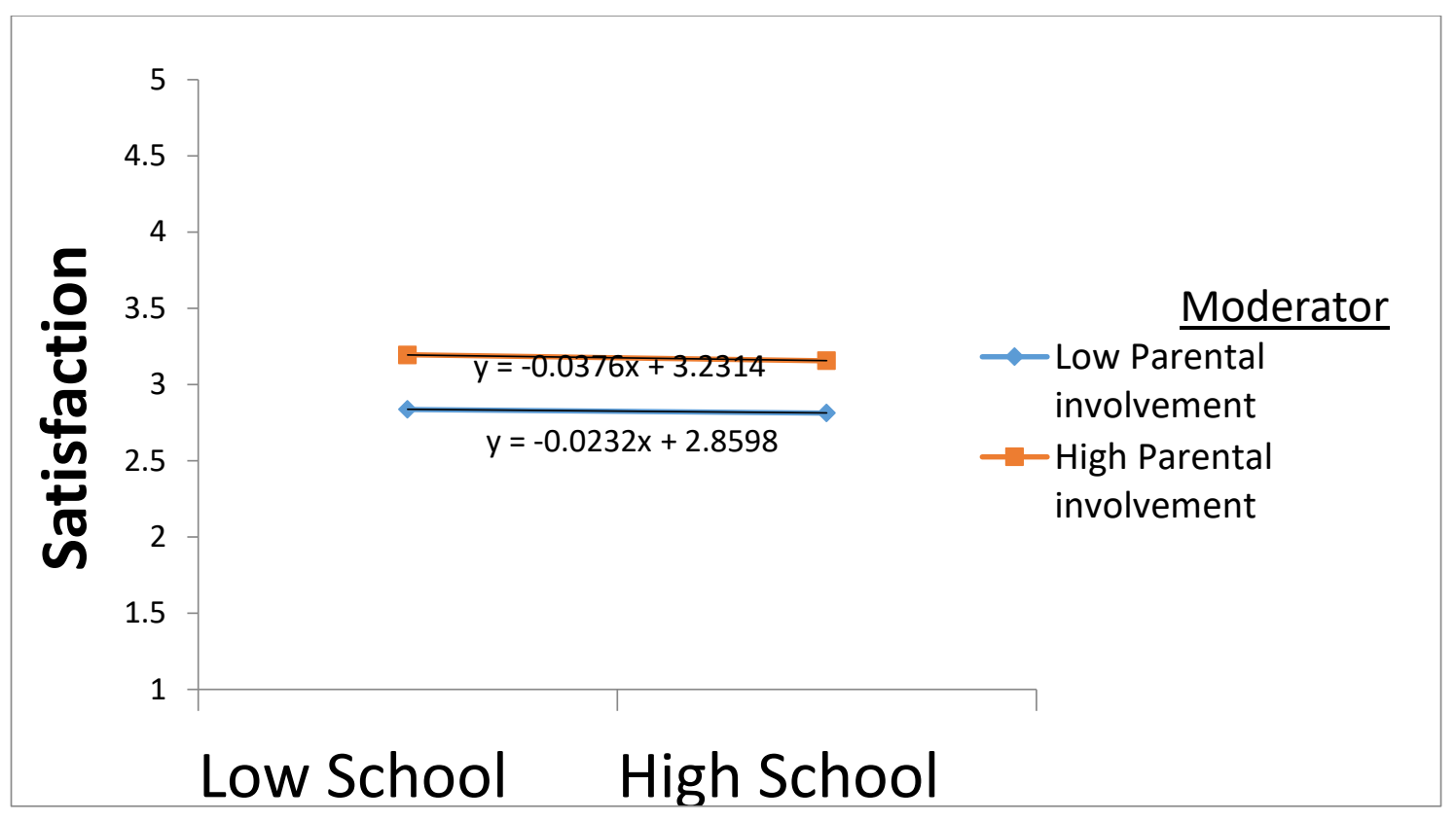

The above given diagram also shows a negative impact of parental involvement on the relationship of school related factors and parental satisfaction. Both the results are comparatively negative in their effect. Hoover-Dempsey and Sandler (2016) in their article define the levels of parental involvement and state that parental involvement may be influenced by two factors which are categorized as implicit when the parent decided to involve and explicit when the parent involves due to external factors as is the case in the present pandemic context. The moderation results suggest that parent might be resenting the fact that the school is placing their burden on the parents. Similar sentiments were expressed by the parents in personal interactions undertaken as a part of the study.

The study has been successful in bring to fore the following points for discussion.

- Schools expect the parents to play the role of the new normal study buddies wherein Parental involvement is highly needed.

- The parents are not satisfied with the new normal because they are having the involvement in their children's education.

- The schools are considering the perception of the parents to improve online education.

- Parental perception of online education does not impact the Parent's satisfaction.

- Schools are trying to satisfy parental expectations and needs.

\section{Conclusion:}

Parental satisfaction with the online mode of education is riddled with doubts questions and queries. The parents seem to have a sense of security with the traditional schooling. Though there is dissatisfaction with the online mode of education yet the need and requirements of time and space have managed to render these points of dissatisfaction as minor not absolute. The amount of parental involvement towards there wards schooling had increased drastically, wherein it will be easy for the educated parents and the parents who are at home (Home maker) to guide the children. The children have started to interact with people less so that they are 
lacking with some social skills. The perception of the parents are not satisfied. The schools, parents, children are trying their best to adopt to the new normal.

\section{References:}

Abuhammad, S. (2020). Barriers to distance learning during the COVID-19 outbreak: A qualitative review from parents' perspective. Heliyon, 6(11), e05482.

https://doi.org/10.1016/j.heliyon.2020.e05482

Bokayev, B., Torebekova, Z., Davletbayeva, Z., \& Zhakypova, F. (2021). Distance learning in Kazakhstan: estimating .parents' satisfaction of educational quality during the coronavirus. Technology, Pedagogy and Education, 30(1), 27-39. https://doi.org/10.1080/1475939X.2020.1865192

Bordoloi, R., Das, P., \& Das, K. (2021). Perception towards online/blended learning at the time of Covid-19 pandemic: an academic analytics in the Indian context. Asian Association of Open Universities Journal, 16(1), 41-60. https://doi.org/10.1108/aaouj-09-2020-0079

Davis, D. D., Bagozzi, R., \& Warshaw, P. R. (1989). User acceptance of computer technology: A comparison of two theoretical models. Management Science, 35(8), 982-1003.

David Robson (2020). How Covid-19 is changing the world's children. https://www.bbc.com/future/article/20200603-how-covid-19-is-changing-the-worlds-children

Dong, C., Cao, S., \& Li, H. (2020). Young children's online learning during COVID-19 pandemic: Chinese parents' beliefs and attitudes. Children and Youth Services Review, 118(August), 105440. https://doi.org/10.1016/j.childyouth.2020.105440

Fegert, J. M., Vitiello, B., Plener, P. L., \& Clemens, V. (2020). Challenges and burden of the Coronavirus 2019 (COVID-19) pandemic for child and adolescent mental health: A narrative review to highlight clinical and research needs in the acute phase and the long return to normality. Child and Adolescent Psychiatry and Mental Health, 14(1), 1-11. https://doi.org/10.1186/s13034-020-00329-3

Gilbert, A. S., Schmidt, L., Beck, A., Kepper, M. M., Mazzucca, S., \& Eyler, A. (2021). Associations of physical activity and sedentary behaviors with child mental well-being during the COVID-19 pandemic. BMC Public Health, 21(1), 1-12. https://doi.org/10.1186/s12889021-11805-6

Garbe, A., ogurlu, U., Logan, N., \& Cook, P. (2020). Parents' Experiences with Remote Education during COVID-19 School Closures. American Journal of Qualitative Research, 4(3), 45-65. https://doi.org/10.29333/ajqr/8471

Garrison, D. R., \& Kanuka, H. (2004). Blended learning: Uncovering its transformative potential in higher education. Internet and Higher Education, 7(2), 95-105. https://doi.org/10.1016/j.iheduc.2004.02.001

Gnanasambandam, C., \& Gomes, M. (2012). Online and upcoming: The Internet' s impact on India. December.

Hoover-Dempsey, K. V., \& Sandler, H. M. (1997). Why do parents become involved in their children's education? Review of Educational Research, 67(1), 3-42. https://doi.org/10.3102/00346543067001003Imran Khan Assistant Professor, S. (2021). 
Online Classes Amid The Covid-19 Pandemic: Parents Perspective. Journal of Contemporary Issues in Business and Government, 27(1), 2021. https://cibg.org.au/

Insani, A., Yufiarti, \& Yetti, E. (2021). Parental Involvement and Mothers' Employment on Children's Independence During Covid-19 Pandemics. JPUD - Jurnal Pendidikan Usia Dini, 15(1), 22-40. https://doi.org/10.21009/jpud.151.02

Jaime Saavedra, March 30, 2020 (https://blogs.worldbank.org/education/educational-challengesand-opportunities-covid-19-pandemic)

Lau, E. Y. H., \& Lee, K. (2020). Parents' Views on Young Children's Distance Learning and Screen Time During COVID-19 Class Suspension in Hong Kong. Early Education and Development, O0(00), 1-18. https://doi.org/10.1080/10409289.2020.1843925

Livingstone, S., Mascheroni, G., Dreier, M., Chaudron, S., \& Lagae, K. (2015). How parents of young children manage digital devices at home: The role of income , education and parental style. EU Kids Online, September, 3-25.

López-Pérez, M. V., Pérez-López, M. C., \& Rodríguez-Ariza, L. (2011). Blended learning in higher education: Students' perceptions and their relation to outcomes. Computers and Education, 56(3), 818-826. https://doi.org/10.1016/j.compedu.2010.10.023

Mascheroni, G., Livingstone, S., Dreier, M., \& Chaudron, S. (2016). Learning Versus Play or Learning Through Play? How Parents' Imaginaries, Discourses and Practices Around Icts Shape Children'S (Digital) Literacy Practices. Media Education, 7(2), 261-280. https://doi.org/10.14605/MED721606

McCormack, G. R., Doyle-Baker, P. K., Petersen, J. A., \& Ghoneim, D. (2020). Parent anxiety and perceptions of their child's physical activity and sedentary behaviour during the COVID19 pandemic in Canada. Preventive Medicine Reports, 20, 101275. https://doi.org/10.1016/j.pmedr.2020.101275 Mirza, A. A. \& Al-Abdulkareem, M. (2011). Models of e-learning adopted in the Middle East. Applied Computing and Informatics journal, Vol. 9, No. 2. Pp. 83-93.

Soumik Sarkar 2020, Adamas University (https://adamasuniversity.ac.in/a-brief-history-ofonline-education/)

Tso, W. W. Y., Wong, R. S., Tung, K. T. S., Rao, N., Fu, K. W., Yam, J. C. S., Chua, G. T., Chen, E. Y. H., Lee, T. M. C., Chan, S. K. W., Wong, W. H. S., Xiong, X., Chui, C. S., Li, X., Wong, K., Leung, C., Tsang, S. K. M., Chan, G. C. F., Tam, P. K. H., ... 1p, P. (2020). Vulnerability and resilience in children during the COVID-19 pandemic. European Child and Adolescent Psychiatry, 0123456789. https://doi.org/10.1007/s00787-020-01680-8

Yamamoto, Y., \& Holloway, S. D. (2010). Parental expectations and children's academic performance in sociocultural context. Educational Psychology Review, 22(3), 189-214. https://doi.org/10.1007/s10648-010-9121-z

Yee, R. C. S. (2011). Perception of Online Learning in an Australian University: Malaysian Student's Perspectives. PhD Dissertation, 1-263.

Zaccoletti, S., Camacho, A., Correia, N., Aguiar, C., Mason, L., Alves, R. A., \& Daniel, J. R. (2020). Parents' Perceptions of Student Academic Motivation During the COVID-19 Lockdown: A Cross-Country Comparison. Frontiers in Psychology, 11(December), 1-13. https://doi.org/10.3389/fpsyg.2020.592670 